\section{Applying the Fuzzy Delphi Method for determining socio-ecological factors that influence adherence to mammography screening in rural areas of Mexico}

\author{
Aproximación Fuzzy Delphi para determinar \\ los factores socioecológicos que influyen \\ en la adherencia a la mastografía en \\ áreas rurales de México
}

\author{
Abordagem Fuzzy Delphi para determinar os \\ fatores socioecológicos que influenciam \\ a adesão à mamografia de rastreio em \\ áreas rurais do México
}

\author{
1 Universidad Popular \\ Autónoma del Estado de \\ Puebla, Puebla, México. \\ 2 Instituto Mexicano del \\ Seguro Social, Cuernavaca, \\ México. \\ Correspondence \\ A. P. Sánchez-Lezama \\ Universidad Popular \\ Autónoma del Estado de \\ Puebla. \\ 21Sur 1103, Puebla, Puebla \\ 72410, México. \\ paolas25mx@hotmail.com
}

\begin{abstract}
In Mexico, regular participation in mammography screening is low, despite higher survival rates. The objective of our research is to highlight healthcare procedures to be optimized and target areas to encourage investment and to raise awareness about the benefits of early diagnosis. Those socio-ecological factors (community, interpersonal and individual) were collected through a review of literature and based on the spatial interaction model of mammography use developed by Mobley et al. The opinion of diverse groups of experts on the importance of those factors was collected by survey. The Fuzzy Delphi Method helped to solve the inherent uncertainty of the survey process. Our findings suggest that population health behaviors, proximity-density to facilities/ physicians and predisposing factors are needed to increase the screening rate. Variations in expert group size could affect the accuracy of the conclusions. However, the application of the enhanced aggregation method provided $a$ group consensus that is less susceptible to misinterpretation and that weighs the opinion of each expert according to their clinical experience in mammography research.
\end{abstract}

Mammography; Rural Areas; Methods
Ana Paola Sánchez-Lezama 1

Judith Cavazos-Arroyo 1

Cidronio Albavera-Hernández ${ }^{2}$

\section{Resumen}

En México la participación regular en mastografía reporta baja frecuencia, aun cuando ésta incrementa la supervivencia. El objetivo de esta investigación es destacar procedimientos que necesitan ser optimizados y áreas necesitadas de inversión, con el fin de incrementar la concientización acerca de los beneficios del diagnóstico temprano. Tales características socioecológicas (comunitarias, interpersonales e individuales) fueron puestas en listas a través de la revisión de la literatura específica y el modelo de interacción espacial del uso de mastografía, desarrollado por Mobley et al. La opinión de los expertos, respecto a la importancia de dichas características, fue recogida por una encuesta, aplicando el método Fuzzy Delphi para reducir la incertidumbre implícita. Nuestros hallazgos sugieren que las conductas de salud de la población, proximidad y densidad de facilidades y médicos, así como factores de predisposición, son necesarios para incrementar las tasas de examen. El uso de grupos de expertos desiguales en tamaño podría afectar a la fiabilidad de las conclusiones. La aplicación de un método de agregación modificado proporcionó un consenso grupal menos sensible a una malinterpretación, además de ponderar la importancia de cada experto según su experiencia en investigaciones con mastografía.

Mamografía; Zonas Rurales; Métodos 


\section{Introduction}

Among Latin American women, breast cancer is one of the most common causes of malignant tumors, surpassing cervical uterine cancer 1 . Patient survival rates have been related to the stage at diagnosis, therefore early detection of a growing breast tumor is of vital importance. Regular participation in exploration activities such as mammography is known to increase the likelihood of early diagnosis, thereby increasing the survival rate by up to $98.1 \%$ within at least 5 years of breast cancer identification 2,3 . Nevertheless, in Mexico $80 \%$ of diagnosed cases are at advanced stages 4 .

In Mexican populations, breast cancer detection coverage between 2007 and 2012 was below the national target of $21.6 \%$ for females aged between 45 and 64 5. In 2007, a low rate of mammography of only $16 \%$ was reported in rural areas among women between the ages of 40 and 496 . Understanding the reasons for the low participation rate in mammography among the Mexican female population is needed to change people's attitudes and resolve institutional problems in promoting screening tests. The identification of the socio-ecological (individual, interpersonal and intermediate/community) factors involved in the adoption of mammography is vital for three reasons: (1) to attain optimal survival outcomes, (2) to identify the crucial socio-ecological factors towards maximizing the efficiency of Social Marketing Campaigns and (3) to define whether Social Marketing Campaigns should be focused at the public health level, i.e. behavior affected by income, and/or at individual level i.e. behavior influenced by attitudes 7 .

In situations that require expert judgment, i.e. the socio-ecological factors that affect mammography participation, some uncertainty and ambiguity is to be expected because of the disparity between meanings and interpretations of opinions 8,9 . Thus, these conjectures cannot be accurately represented quantitatively 9 . The combination of the Fuzzy Set Theory and Delphi Method, named the Fuzzy Delphi Method 10, models the uncertainty and vagueness mathematically, addressing the inaccuracy which is intrinsic in human reasoning from using linguistic terms, i.e. "not important", "less important", so as to reflect their preferences 9,11. A fuzzy set is a collection of elements characterized by a membership function. The grade of membership is defined as a possibility distribution and ranges between zero and one ${ }^{12}$. The nearer the value to unity, the greater the degree of belonging. For example, consider a fuzzy set as an application in supporting medical diagnosis for five diseases, where we have a set of symptoms $S=$ \{chest-pain, cough, stomach pain, headache, temperature and a set of diagnoses $D=$ \{fever, malaria, typhoid, stomach problem, chest problem\}. The state of a patient is determined by his/her medical test results. However, sometimes there is lack of knowledge, thus the information cannot be classified. Therefore, a solution is derived from the use of a degree of membership 13. The Fuzzy Set Theory is designed to extract a primary possible outcome resembling human reasoning. The Fuzzy Set Theory rationalizes uncertainty to generate and solve the group decision 10,12,14. Consequently, to obtain a more representative description of the significance of the factors in reduced mammography participation, this study applies the Fuzzy Delphi Method which is optimized by the consistency aggregation method. The consistency aggregation method aggregates the fuzzy individual opinions into a group consensus using a consistency index. It is based on similarity and distance indices for the comparison between experts' fuzzy opinions 15 .

Our study design overcomes variations in medical opinions in Mexican breast cancer by implementing Fuzzy Set Theory through the following objectives: (1) to review the literature in order to generate a list of various features influencing mammography attendance and; (2) to apply the Fuzzy Delphi Method via the Consistency Aggregation Method to form a consensus of expert opinion and determine the most significant factors that affect breast cancer screening participation or avoidance behavior. The results therefore represent the first step of an investigation with two goals: (1) to guide the implementation of theoretically designed educational programs and (2) to provide the authorities responsible for breast cancer detection programs in Mexico with a view of the procedures to be optimized and target the areas in which to encourage investment. The aim is to raise awareness about breast cancer and the benefits of early diagnosis.

\section{Methodology}

A detailed list of possible determining factors for women's participation in early mammography detection screening was created through an exhaustive review of literature and based on the spatial interaction model of mammography use 16 (Table 1). This model considers the effects of hypothetical constructs - those that cannot be directly observed and are measured indirectly by means of observable items in a questionnaire - therein called latent variables 17 , at the political, cultural, social and institutional level. 
Overall group opinion rating of factors which influence mammography participation defined as scores using the Fuzzy Delphi Method and represented Fuzzy Delphi Method variables.

\begin{tabular}{|c|c|c|c|c|c|}
\hline \multirow[t]{2}{*}{ Latent variable } & \multirow[t]{2}{*}{ Variable } & \multicolumn{3}{|c|}{ Group fuzzy opinion } & \multirow[t]{2}{*}{$\mathrm{s}_{\mathrm{k}}$} \\
\hline & & Min. & Opt. & Max. & \\
\hline \multirow[t]{8}{*}{ Enabling/Disabling } & A1. Asset index * & 7.02 & 8.15 & 9.22 & $8.13^{* *}$ \\
\hline & A2. Rate of occurrence & 5.35 & 6.46 & 7.39 & 6.4 \\
\hline & A3. Insurance status & 8.25 & 8.99 & 9.47 & 8.90 ** \\
\hline & A4. Civil status & 2.86 & 3.79 & 5.21 & 3.95 \\
\hline & A5. Working situation in last week & 5.22 & 6.32 & 7.89 & 6.47 \\
\hline & A6. Secondary job & 4.52 & 5.11 & 6.37 & 5.33 \\
\hline & A7. Time dedicated to care of children, the sick and/or elderly & 4.85 & 5.89 & 7.34 & 6.03 \\
\hline & A8. Number of children aged 12 and under & 6.14 & 7.46 & 8.28 & 7.29 ** \\
\hline \multirow[t]{4}{*}{ Predisposing } & B1. Mammogram prior to the study period & 6.41 & 7.61 & 8.65 & 7.56 \\
\hline & B2. Woman's age & 7.64 & 8.49 & 9.38 & 8.5 \\
\hline & B3. Indigenous condition & 7.43 & 8.88 & 9.54 & 8.62 \\
\hline & B4. Level of education & 8.08 & 9.19 & 9.47 & 8.91 ** \\
\hline \multirow[t]{9}{*}{ Need } & C1. Number of live births & 3.76 & 4.35 & 6.06 & 4.72 \\
\hline & C2. Age at first childbirth & 5.01 & 5.85 & 6.6 & 5.82 ** \\
\hline & C3. Date of latest Pap smear & 5.09 & 6.02 & 7.21 & 6.11 ** \\
\hline & C4. Sick days (last 4 weeks) & 4.07 & 4.77 & 6.44 & 5.1 \\
\hline & C5. High blood pressure & 3.09 & 3.75 & 5.2 & 4.01 \\
\hline & C6. Heart disease & 3.62 & 4.68 & 5.92 & 4.74 \\
\hline & C7. High cholesterol/ triglycerides & 3.28 & 4.21 & 5.79 & 4.43 \\
\hline & C8. Doctor's consultation (last 4 weeks) & 4.41 & 5.16 & 6.61 & 5.4 \\
\hline & C9. Preventive medicine consultation & 7.31 & 8.15 & 9.05 & $8.17^{\text {** }}$ \\
\hline \multirow[t]{3}{*}{ Stressors } & D1. Women living alone & 3.16 & 4.04 & 4.95 & 4.05 \\
\hline & D2. Intensity of travel fares $* \star \star$ & 4.84 & 5.71 & 6.85 & 5.8 \\
\hline & D3. Social gap index\# & 8.13 & 9.15 & 9.77 & $9.01 * *$ \\
\hline Social integration, & E1. Homes which have provided social support & 2.59 & 3.42 & 4.55 & 3.52 \\
\hline support and & E2. Homes which have received social support & 3.22 & 4.24 & 5.07 & 4.18 \\
\hline \multirow[t]{2}{*}{ behavioral settings } & E3. Homes participating in community activities & 3.93 & 5.08 & 5.95 & 4.99 \\
\hline & E4. Women who have worked at some time & 4.83 & 6.16 & 6.92 & $5.97^{* *}$ \\
\hline
\end{tabular}

(continues)

On an individual level the model evaluates the characteristics which enable or prohibit mammography participation: the interpersonal level (locality) includes vicinity specificity which impacts perceived individual risk or the search for health care information; the intermediate level (municipality) covers the physical and social environment affected by infrastructure resources supporting community life 18 . The fourth level (state) is omitted from this investigation, because at present the data is available for 13 out of 32 states. The variables used herein, corresponding to each latent variable of the spatial model, are shown in Table 1.

\section{The Fuzzy Delphi Method}

The creation of a large number of variables complicates the construction and assessment of models 19. The Delphi Method has been widely used to obtain a constant flow of expert opinions through survey. Questions come from related literature and those recommended by experts. The Delphi approach has three characteristics: anonymous responses, interaction and controlled feedback, as well as a statistical group response 9 . The questionnaire procedure requires asking the opinion of experts on multiple occasions, which results in certain difficulties, such as: (1) failure to take fuzziness into account leading to misinterpretation of the opinions; (2) 
Table 1 (continued)

\begin{tabular}{|c|c|c|c|c|c|}
\hline \multirow[t]{2}{*}{ Latent variable } & \multirow[t]{2}{*}{ Variable } & \multicolumn{3}{|c|}{ Group fuzzy opinion } & \multirow[t]{2}{*}{$\mathrm{S}_{\mathrm{k}}$} \\
\hline & & Min. & Opt. & Max. & \\
\hline \multirow[t]{5}{*}{ Social relationships } & F1. Homes participating in co-ops, associations or activities & 3.91 & 4.67 & 5.87 & 4.82 \\
\hline & F2. Women who receive financial support & 4.59 & 5.96 & 6.89 & 5.82 \\
\hline & F3. Women who are accompanied to the doctor & 6.14 & 7.25 & 8.16 & 7.18 ** \\
\hline & F4. Women who are listened to & 5.79 & 6.77 & 7.9 & 6.82 ** \\
\hline & F5. Women who receive food and housing support & 5.44 & 6.29 & 7.28 & 6.34 \\
\hline Population health & G1. Women who trust their doctor & 7.23 & 8.08 & 9.05 & 8.12 ** \\
\hline \multirow[t]{7}{*}{ behaviors or norms } & G2. Women who follow the doctor's advice & 7.99 & 8.41 & 9.44 & $8.61 * \star$ \\
\hline & G3. Self-medicating homes & 4.42 & 6 & 6.8 & 5.74 \\
\hline & G4. Women with abnormal Pap smears & 6.82 & 7.62 & 8.48 & 7.64 \\
\hline & G5. Women with medical follow-up of abnormal Pap results & 7.28 & 8.04 & 8.77 & 8.03 ** \\
\hline & G6. Women with medical follow-up of abnormal mammogram results & 8.83 & 9.79 & 9.91 & $9.51 *$ \\
\hline & G7. Women with a definite birth control method & 4.36 & 5.13 & 6.21 & 5.23 \\
\hline & G8. Women who use temporary birth control & 5.07 & 5.76 & 6.67 & 5.83 \\
\hline Proximity, density & H1. Density of radiologists & 7.63 & 8.5 & 9.23 & 8.45 ** \\
\hline of facilities and & H2. Density of doctors & 6.65 & 7.85 & 8.77 & 7.75 \\
\hline \multirow[t]{7}{*}{ physicians } & H3. Density of nurses & 6.18 & 6.96 & 8.04 & 7.06 \\
\hline & H4. Availability of health centers & 7.46 & 8.3 & 9.22 & 8.32 ** \\
\hline & H5. Availability of Mexican Social Security Institute - opportunities program clinics & 7.04 & 7.95 & 9 & 8 \\
\hline & H6. No. of Health Department mammographs & 8.92 & 9.56 & 9.85 & $9.44 * *$ \\
\hline & H7. Localities visited by mobile health caravans or brigades & 7 & 7.79 & 9.04 & 7.95 \\
\hline & H8. Health units which give community health workshops & 7.73 & 8.51 & 9.53 & 8.59 * \\
\hline & H9. Average number of community health workshops given in health units & 7.09 & 7.77 & 9.15 & 8 \\
\hline Crowding, & 11. Longer than average waiting time for a consultation & 5.95 & 7.27 & 8.07 & 7.10 * \\
\hline scheduling and & 12. Perception of better medical attention in homes benefitting from & 5.05 & 6.22 & 7.15 & 6.14 \\
\hline convenience & Opportunities program & & & & \\
\hline
\end{tabular}

Max.: maximum of expert's opinion; Min.: minimum of expert's opinion; Opt.: optimal of expert's opinion; $S_{k}$ : real number calculated with the defuzzification procedure.

* Accumulated home assets 6;

** With higher values than the thresholds: 6.94 (enabling/disabling), 8.68 (predisposing), 5.56 (need), 6.29 (stressors), 5.04 (social integration, support and behavioral settings), 6.54 (social relationships), 7.96 (population health behaviors or norms), 8.31 (proximity and density of facilities, physicians), 6.62 (crowding, scheduling and convenience). The thresholds were calculated using the procedure step 5 as described in Methodology;

*** Proportion of economic activity dedicated in the last week (Monday through Sunday), plus the average transport time to and from work (in hours) 12;

\# Summarizes different aspects of poverty, considering 13 deficiency markers: education, access to health, basic services, housing quality and home assets 17 .

systematic suppression of variables, i.e. sometimes the factors that are selected by at least $50 \%$ of the experts are retained; (3) process losses in coordination and communication; (4) repeatedly surveying the experts is more costly and timeconsuming 10. Furthermore, there is a noteworthy problem to solve the fuzziness (expected ambiguity) of common understanding of expert opinions (Dirección General de Información en Salud. Recursos Humanos, Físicos y Materiales de la Secretaría de Salud y los Servicios Estatales de Salud. http://www.sinais.salud.gob.mx/bases dedatos/recursos.html; Unidades Médicas del Sector Público. http://www.sinais.salud.gob.mx/ basesdedatos/unidadesmedicas.html, accessed on $15 /$ May/2011) 8 . To overcome these difficul- ties, Murray et al. 10 proposed to apply the Fuzzy Delphi Method to group decisions. This method is based on a similarity function to assess the level of agreement between experts. The Fuzzy Delphi Method assures no misinterpretation of expert opinions since it considers the fuzziness that every survey process has to deal with 8 . Thus, more objective evaluation factors can be determined through statistical analysis since the efficiency and quality of questionnaires are enhanced 8,9. Some of the more representative strengths of the Fuzzy Delphi Method are: time saving, fewer surveys, increased recovery rate, and guarantee of completeness and consistency of the group opinion 19. Additionally, the Similarity Aggregation Method was suggested to help solve the 
fuzziness problem in the consensus of experts (Consejo Nacional de Evaluación de la Política de Desarrollo Social. Índice de Rezago Social 2005 a Nivel Municipal y por Localidad. http://www.co neval.gob.mx/cmsconeval/rw/pages/medicion/ cifras/indicederezago.es.do, accessed on $01 /$ Jun/2011). The Similarity Aggregation Method procedure introduces a similarity index to measure consistency among survey responders. Lu et al. 15 enriched the methodology through the Consistency Aggregation Method to improve the way in which similarity between fuzzy numbers is calculated. In this research, modified measures of similarity and distance were thus combined to obtain the weights of each individual opinion and finally the aggregation weights were determined through the algorithm stated as follows.

\section{- Adapted Consistency Aggregation Method 15}

Step 1: calculate the similarity $S_{w}\left(\tilde{R}_{i}, \tilde{R}_{j}\right)$ between each pair of experts' opinions $\tilde{R}_{i}=a_{i}, b_{i}, c_{i}$ and $\widetilde{R}_{j}=a_{j}, b_{j}, c_{j}$ for the 13 experts by:

$S_{w}\left(\tilde{R}_{i}, \tilde{R}_{j}\right)=\frac{\int_{x}\left(\min \left\{\mu_{\tilde{R}_{i}}(x), \mu_{\tilde{R}_{j}}(x)\right\}\right)^{2} d x}{\int_{x}\left(\min \left\{\mu_{\tilde{R}_{i}}(x), \mu_{\tilde{R}_{j}}(x)\right\}\right)^{2} d x}=$

$=\frac{\sum_{j=1 \text { and } j \neq i}\left(\min \left\{\mu_{\tilde{R}_{i}}(x), \mu_{\tilde{R}_{j}}(x)\right\}\right)^{2} d x}{\sum_{j=1 \text { and } j \neq i}\left(\max \left\{\mu_{\tilde{R}_{i}}(x), \mu_{\tilde{R}_{j}}(x)\right\}\right)^{2} d x}$

where the triangular membership function $\mu_{\widetilde{R}_{i}}(x)$ is given by:

$\mu_{\tilde{R}_{i}}(x)\left\{\begin{array}{l}0 \quad \text { if } x<\lambda-\alpha, \lambda+\beta<x \\ \frac{(x-\lambda-\alpha))}{\alpha} \text { if } \lambda-\alpha \leq x<\lambda \\ \frac{((x+\beta)-x)}{\beta} \text { if } \lambda \leq x \leq \lambda+\beta\end{array}\right.$

where $\lambda-\alpha=\alpha_{l}, \lambda=b_{i}, \lambda+\beta=c_{i}$ (Figure 1). Let us consider as an example for only two experts' opinions, $\tilde{R}_{1}=\left(a_{1}, b_{1}, c_{1}\right)=(5,7,9)$ and $\tilde{R}_{2}=\left(a_{2}, b_{2}, c_{2}\right)=(1,3,5)$. Now using the membership function equation (2) we obtain:

$S_{w}\left(\tilde{R}_{1}, \tilde{R}_{1}\right)=1, S_{w}\left(\tilde{R}_{1}, \tilde{R}_{2}\right)=0, S_{w}\left(\tilde{R}_{2}, \tilde{R}_{2}\right)=1$,

however, for a left $\left(a_{i}, b_{i}, 0\right)$ or right $\left(0, b_{i}, c_{i}\right)$ triangular fuzzy set the respective membership function defined also by Park et al. 20 was applied. If $a_{i}=b_{i}=c_{i}$ in a triangular fuzzy number, we obtain a real crisp number 15 , therefore its membership function is equal to 1 for the given real number and 0 for all other real numbers 21 .

Step 2: calculate the distance $d\left(\tilde{R}_{i}, \tilde{R}_{j}\right)$ between each pair of $\widetilde{R}_{i}$ and $\tilde{R}_{j}$ by :
$d\left(\tilde{R}_{i}, \tilde{R}_{j}\right)=\frac{D\left(\tilde{R}_{i}, \tilde{R}_{j}\right)}{D^{*}\left(\tilde{R}_{i}, \tilde{R}_{j}\right)}$

where $D\left(\tilde{R}_{i}, \tilde{R}_{j}\right)$ is the normalized distance measure defined as follows:

$D\left(\tilde{R}_{i}, \tilde{R}_{j}\right)=\frac{1}{2}\left(d_{H}\left(\tilde{R}_{i}, \tilde{R}_{j}\right)+d_{\text {inf }}\left(\tilde{R}_{i}, \tilde{R}_{j}\right)\right)$

with $d_{H}\left(\tilde{R}_{i}, \tilde{R}_{j}\right)$ the Hamming distance based on the weighted one defined by Merigó 22 and $d_{i n f}\left(\tilde{R}_{i}, \tilde{R}_{j}\right)$ are calculated between any two fuzzy numbers $\tilde{R}_{i}=\left(a_{i}, b_{i}, c_{i}\right)=a_{1}, b_{1}, c_{1}$ and $\tilde{R}_{j}=\left(a_{j}, b_{j}, c_{j}\right)=$ $a_{2}, b_{2}, c_{2}$ as follows:

$\left(d_{H}\left(\tilde{R}_{i}, \tilde{R}_{j}\right)=\sum_{m=1}^{3}\left|a_{m}-b_{m}\right|\right.$

$d_{\text {inf }}\left(\tilde{R}_{i}, \tilde{R}_{j}\right)=\inf \left\{d(a, b), a \in \tilde{R}_{i}, b \in \tilde{R}_{j}\right\}$

$D^{*}\left(\tilde{R}_{i}, \tilde{R}_{j}\right)$ represents the largest distance,

$D^{*}\left(\tilde{R}_{i}, \tilde{R}_{j}\right)=\max _{i, j} D\left(\tilde{R}_{i}, \tilde{R}_{j}\right)$

by our distance measure equation (3), we have:

$d\left(\tilde{R}_{1}, \tilde{R}_{1}\right)=0, \mathrm{~d}\left(\tilde{R}_{1}, \tilde{R}_{2}\right)=1, d\left(\tilde{R}_{2}, \tilde{R}_{2}\right)=0$

Step 3: given $\beta \in[0,1]$, let $\beta=\frac{1}{2}$ and calculate the consistency degree $r\left(\tilde{R}_{i}, \widetilde{R}_{j}\right)$ between each pair of experts by:

$r\left(\tilde{R}_{i}, \tilde{R}_{j}\right)=\beta S_{w}\left(\tilde{R}_{i}, \tilde{R}_{j}\right)+(1-\beta)\left(1-d\left(\tilde{R}_{i}, \tilde{R}_{j}\right)\right)$

Step 4: let the degrees of importance of thirteen experts be $e_{i}, i=1, \ldots, 13$.

The degrees of importance are defined according to the years of experience reported by each expert in mammography studies, getting the percentage for each expert over the total years of experience. Then calculate the weighted consistency degree $C\left(E_{i}\right)$ for each expert $\mathrm{E}_{i}$ by:

$C\left(E_{i}\right)=\sum_{j=1}^{12} r\left(\tilde{R}_{i}, \tilde{R}_{j}\right) e_{j}$

Using equation (9) and a given $e_{1}=0.04, e_{2}=$ 0.08 the weighted consistency degrees are $C\left(E_{1}\right)=$ $0.04, C\left(E_{2}\right)=0.08$

Step 5: calculate the aggregation weight $w\left(E_{i}\right)$ of expert $E_{i}$ as follows:

$w\left(E_{i}\right)=\frac{C\left(E_{i}\right)}{\sum_{j=1}^{13} C\left(E_{j}\right)}$

Step 6: aggregate each fuzzy opinion for each feature $k$ into a group fuzzy opinion as:

$\tilde{R}_{k}=\sum_{i=1}^{13} w\left(E_{i}\right)(\bullet) \tilde{R}_{i}=\left(\begin{array}{l}{\left[w\left(E_{i}\right)^{*} a_{1}+\ldots+w\left(E_{13}\right)^{*} a_{13}\right],} \\ {\left[w\left(E_{i}\right)^{*} b_{1}+\ldots+w\left(E_{13}\right)^{*} b_{13}\right],} \\ {\left[w\left(E_{i}\right)^{*} c_{1}+\ldots+w\left(E_{13}\right)^{*} c_{13}\right]}\end{array}\right)=\left(a_{k}, b_{k}, c_{k}\right), k=1, \ldots, 52(11)$

where $(\bullet)$ is the fuzzy multiplication operator 23 .

Thus, the fuzzy opinion for feature $k=1$ is $\tilde{R}_{k}=(2.3332,4.3332,6.3332)$ 
Figure 1

Line plots of group Fuzzy Delphi opinion scores $\left(y\right.$-axis, $\left.S_{k}\right)$ for each latent variable (x-axis) in the spatial interaction model of female mammography use.

1a) Enabling-disabling features

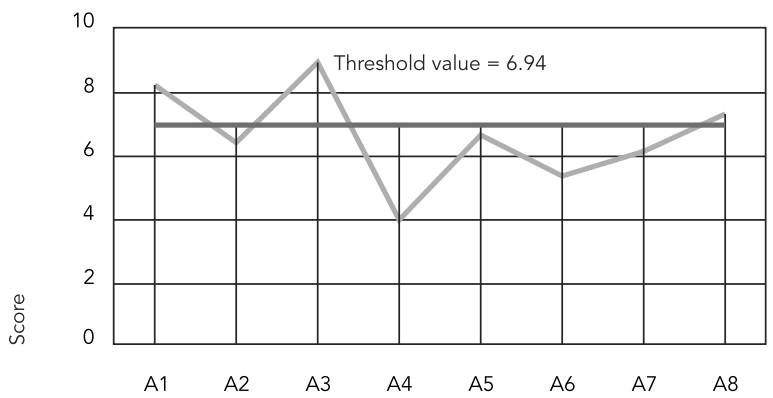

1c) Need features

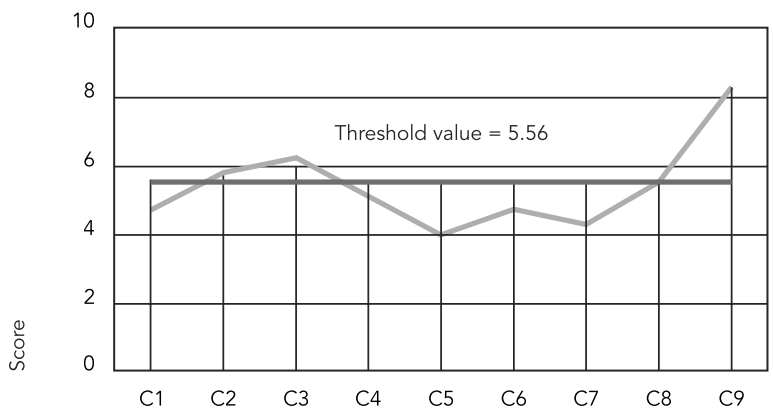

1e) Social integration support and behavioral features

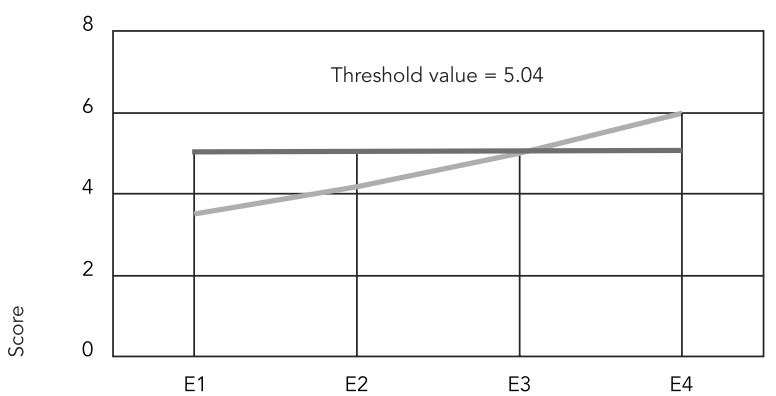

1b) Predisponing features

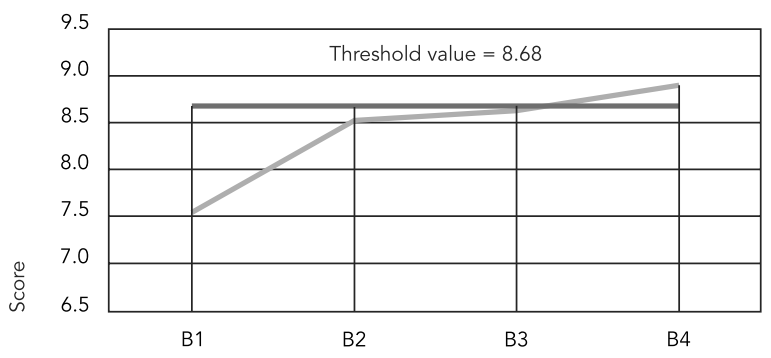

1d) Stressor features

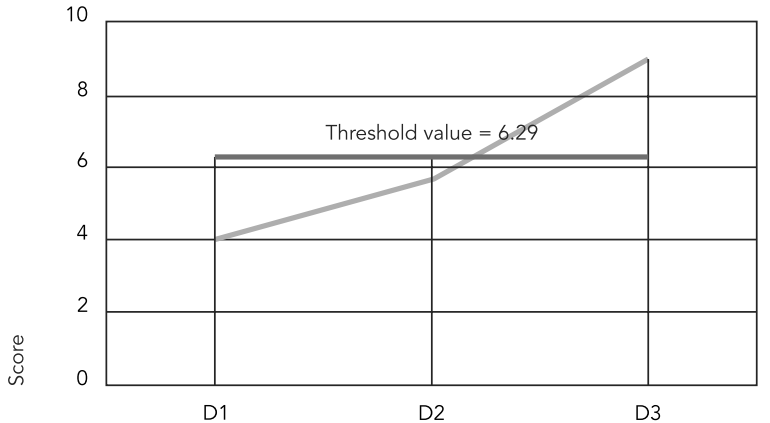

1f) Social relationships features

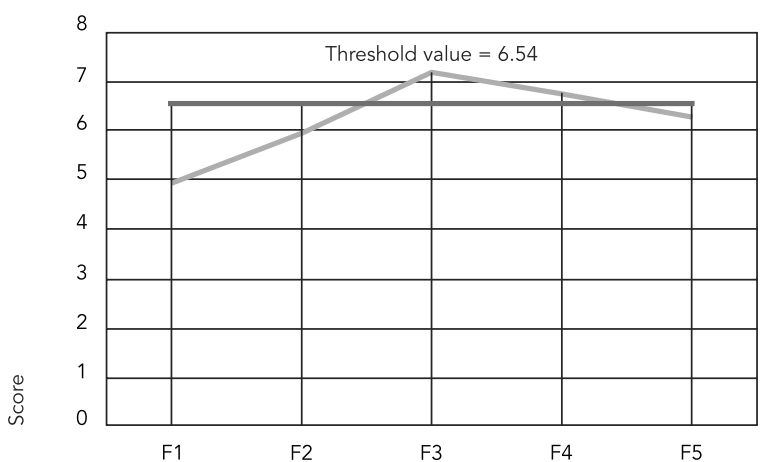

(continues)

The Fuzzy Delphi Method with the Simple Center of Gravity Method proposed by Glumac et al. ${ }^{8}$ and Hsu et al. ${ }^{9}$ was used to achieve consensus regarding the importance of the identified variables. The Simple Center of Gravity Method is the most common method for creating a quantifiable result in fuzzy logic (defuzzification), computing the weighted average of the membership function 24 , as follows. 
1g) Population health behaviors or norms features

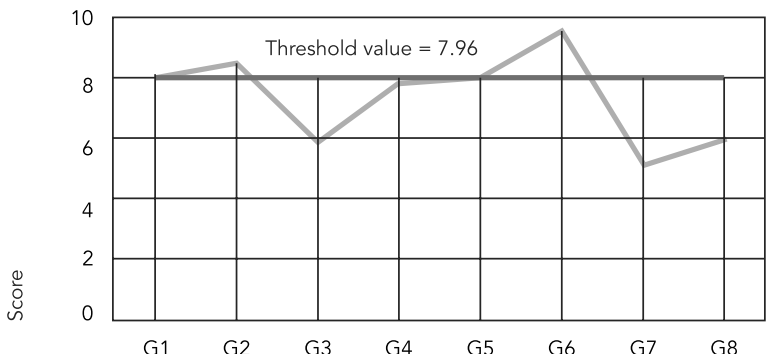

1i) Crowding scheduling and convenience features

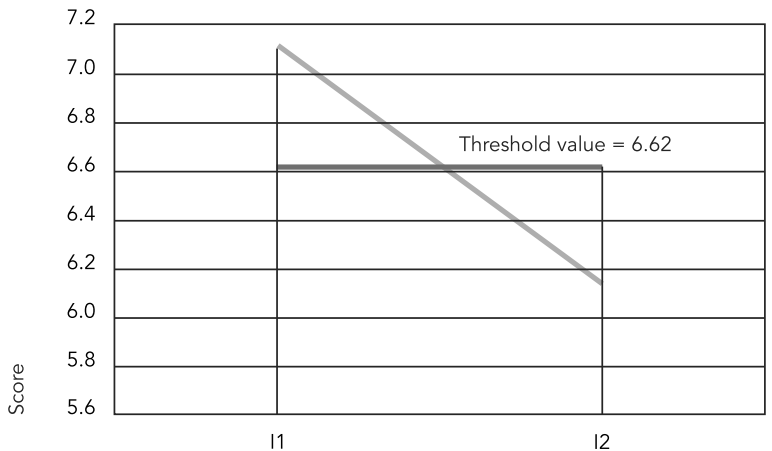

1h) Proximity-density of facilities-physicians features

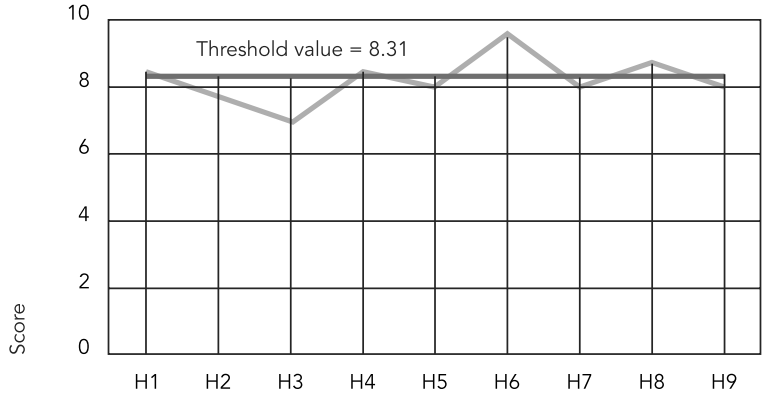

\section{- Deffuzification 9}

The value $S_{k}$ is obtained by:

$S_{k}=\frac{a_{k}+b_{k}+c_{k}}{3}, k=1, \ldots, 52$

A modified approach for Fuzzy Delphi Method is illustrated in Figure 2 with a flow chart for this study. The analysis was performed with $\mathrm{R}$ software (The R Foundation for Statistical Computing, Vienna, Austria; http://www.r-project. org). The methodology with the corresponding modifications, consisted of the following steps:

\section{- First panel evaluation: definition of items}

Validation of a predefined list of variables: in a preliminary survey, experts were asked to approve or, failing that, add the variables they considered pertinent to the initial proposed list, based on the literature review.
- Second panel evaluation: item evaluation by some criterion of importance

Collection of experts' opinions: in a second survey, the triangular fuzzy number was obtained for each expert, which represented the respondents' rate and range of importance of each variable, i.e. the expert gave three values (minimum $-a_{i}$, optimal $-b_{i}$ and maximum level $-c_{i}$ of importance) on a scale of 0 to 10 related to a linguistic description ("very unimportant" to "very important"). In this study, a triangular membership function was implemented, to provide the experts with a simpler evaluation procedure. The three scores obtained per variable and per expert generated a more reliable data analysis 8 .

\section{- Consistency Aggregation Method algorithm}

Setting up overall triangular fuzzy number: separately examining the evaluation of each variable provided by the group of experts and aggregate 
Figure 2

Detailed flow diagram of the Fuzzy Delphi Method implemented to calculate the overall opinion of experts in mammography related research reported in Table 1.

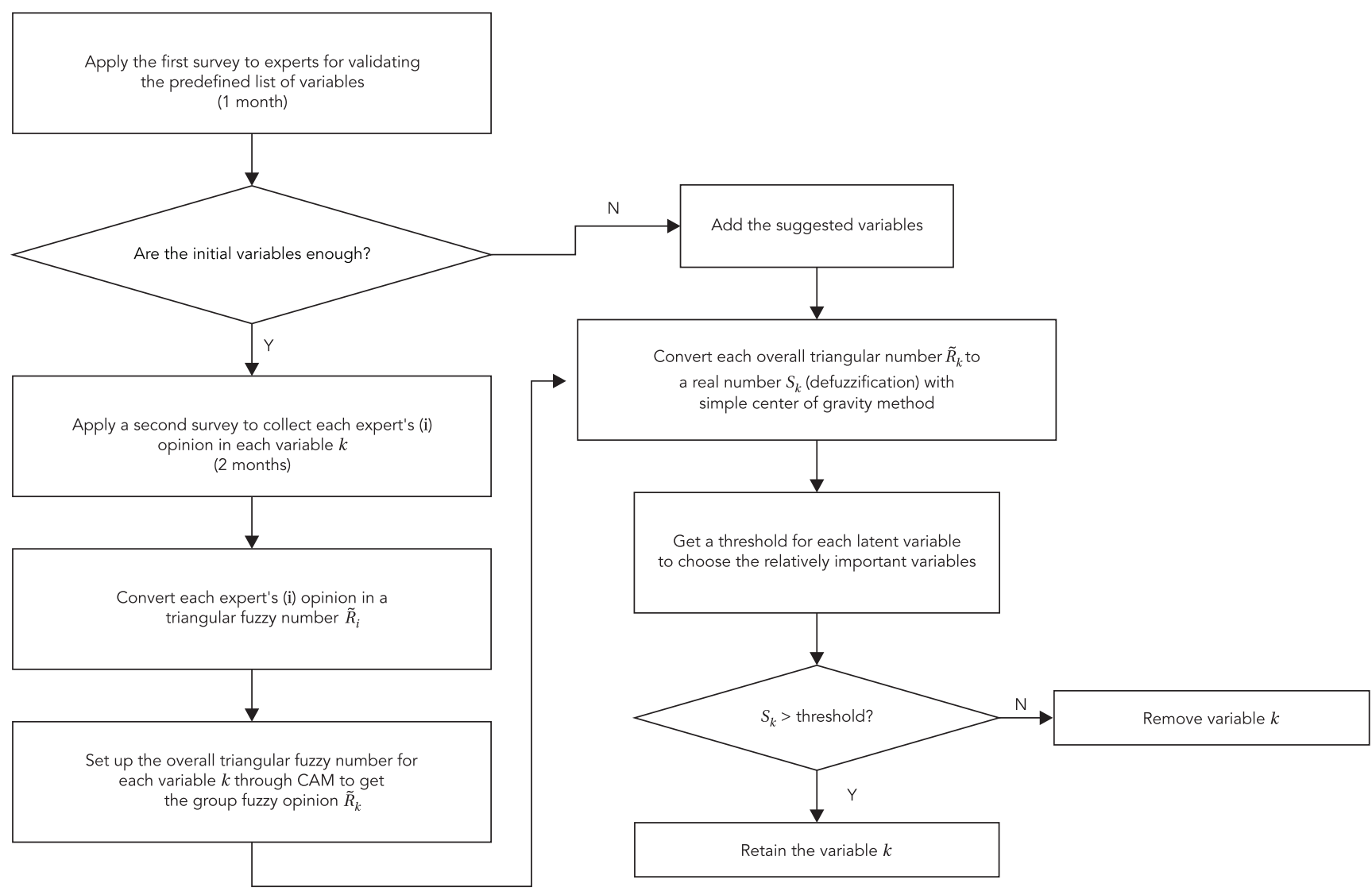

CAM: Consistency Aggregation Method.

the individual fuzzy opinions into a group fuzzy opinion through the modified Consistency Aggregation Method. By the method, the group consensus opinion is achieved based on similarity and distance indices. The aggregation of the fuzzy opinions is calculated from the weighted consistency degree for each expert and aggregated weight 15. An algorithm is illustrated in item Adapted Consistency Aggregation Method to determine the aggregation weights of each individual opinion. The first modification to the original algorithm was the adjustment of the Consistency Aggregation Method, considering either a left or right triangular fuzzy set, to model the unusual answer pattern given by some experts. The second modification was the distance definition in Consistency Aggregation Method, using the Hamming distance for calculation optimization.

\section{- Simple Center of Gravity Method}

Defuzzification: the aim was to convert the overall triangular number to a real number 8 . The Simple Center of Gravity Method 25 for each group fuzzy opinion was used to derive a definite value for each feature. The procedure is shown in item Deffuzification.

\section{- Ho et al. 26 thresholds setting}

Choice of the relatively important variables: variables that presented a value greater than each separately set threshold for each latent variable based on the method of Ho et al. ${ }^{26}$ applied by Ho \& Wang 27, were retained. The cut-off point was determined using the arithmetic mean and the standard deviation of the internal variables 
in each latent variable. The threshold settings were made following Ho et al.'s 26 methodology for variable selection, which avoided the subjectivity in the specification.

\section{Survey design}

The first selection of variables to be evaluated relied mainly on the availability of data taken at individual, local and municipal levels in the rural homes survey (ENCEL 2007) 19, from the National Health Information System (Dirección General de Información en Salud. Recursos $\mathrm{Hu}$ manos, Físicos y Materiales de la Secretaría de Salud y los Servicios Estatales de Salud. http:// www.sinais.salud.gob. $\mathrm{mx} / \mathrm{b}$ asesdedatos/re cursos.html; Unidades Médicas del Sector Público. http://www.sinais.salud.gob.mx/bases dedatos/unidadesmedicas.html, accessed on 15/May/2011) and datasets from the National Council for Evaluation of Social Development Policies (Consejo Nacional de Evaluación de la Política de Desarrollo Social. Índice de Rezago Social 2005 a Nivel Municipal y por Localidad. http://www.coneval.gob.mx/cmsconeval/rw/ pages/medicion/cifras/indicederezago.es.do, accessed on 01/Jun/2011). The ENCEL survey was carried out on women who lived in impoverished areas. This research is focused on rural areas because women living in more deprived areas present additional challenges in terms of the access to health systems, related payment capacity, timely attention, treatment from health care staff and geographical difficulties in reaching care centers, among others 25 .

The two surveys were carried out by sending an e-mail questionnaire to experts and academics in the following fields, viz. epidemiology, demography, economics, sociology, oncology, public health and health sciences. The goal of the first instrument was to refine and validate the initial list of factors obtained from the literature review. For that purpose the survey was submitted to three experts for evaluation, namely an epidemiologist, a demographist and a marketer. Hence, 52 variables corresponding to 9 constructs of the spatial interaction model of mammography use were proposed (Table 1) as inputs for the second questionnaire. A total of 20 experts were contacted to participate in the second stage, 13 of whom agreed, a response rate of $65 \%$. Three sections were included, following the methodology employed by Ho \& Wang 27: basic information (gender, area of specialization, years of specialization in breast cancer and in mammography), questionnaire instructions and finally the definition of variables and responses. The focus of the survey was to ask experts to estimate the importance of each variable as a determining factor in the use of mammography by allocating three values: minimum, optimal and maximum, by means of a 7 -point Likert scale $(0=$ very unimportant, $1=$ quite unimportant, $3=$ unimportant, $5=$ neutral, 7 = important, 9 = quite important and $10=$ very important).

The structure of the experts' disciplines comprised epidemiology (31\%), sociology (23\%), public health (15\%), oncology (15\%), demographics (8\%) and health sciences in the workplace $(8 \%)$; $76.92 \%$ were women. The respondents had an average of 10.12 years' experience in breast cancer research, with a minimum of 3 years and a maximum of 38 . The mean number of years of mammography-related research was 6.58 , with a minimum of 2 and a maximum of 15 . Based on this information, the degrees of importance of 13 experts (Step 4, item Adapted Consistency Aggregation Method) are shown in Table 2. After eliminating the missing values obtained in the ranking of the variables in the second questionnaire, the sample size varied between 9 and 13 experts.

\section{Results}

Those features which showed a real score higher than the threshold value after defuzzification were retained and the remainder discarded. The 20 relatively important factors resulting from the examination process are shown in Table 1 and Figure 3. A description of the variables selected from the expert survey are given and correspond to nine latent variables considered from the spatial interaction model of mammography use: 1) Enabling/disabling: of the eight variables, three were retained, insurance status having the highest score, with 8.90 , followed by asset index and number of children aged 12 and under.

2) Predisposing: only level of education was retained with 8.91 .

3) Need: of the nine characteristics, three were retained, preventive medical consultation having the highest value with 8.17, followed by Pap smear and age at first childbirth.

4) Stressors: of the three variables, only the social gap index was retained with 9.01.

5) Social integration, support and behavioral settings: Of the four factors, only women who have worked at some time was retained with 5.97.

6) Social relationships: of the five variables only two remained, being accompanied to the doctor is seen as the most important with 7.18 followed by women who are listened to.

7) Population health behaviors or norms: only four of the eight variables remained, follow-up of abnormal mammogram results was the most 
Weights (degrees of importance) of the years of experience of each expert in mammography related research to calculate the Fuzzy Delphi Method aggregated opinion defined in Table 1.

\begin{tabular}{|c|c|c|c|c|}
\hline \multirow[t]{2}{*}{ Expert's area } & \multirow[t]{2}{*}{ Gender } & \multirow{2}{*}{$\begin{array}{c}\text { Years of } \\
\text { mammography- } \\
\text { related research }\end{array}$} & \multicolumn{2}{|c|}{ Expert's degrees of importance } \\
\hline & & & $e_{i}$ & $\%$ \\
\hline Public health & $\mathrm{F}$ & 7 & e1 & 0.08 \\
\hline Epidemiology & $\mathrm{F}$ & 10 & e2 & 0.12 \\
\hline Epidemiology & $\mathrm{F}$ & 4 & e3 & 0.05 \\
\hline Epidemiology & M & 3 & $\mathrm{e} 4$ & 0.04 \\
\hline Sociology & M & 2 & e5 & 0.02 \\
\hline Sociology & $\mathrm{F}$ & 7 & e6 & 0.08 \\
\hline Public health & $\mathrm{F}$ & 5 & e7 & 0.06 \\
\hline Oncology & $\mathrm{F}$ & 8 & e8 & 0.09 \\
\hline Health sciences in the workplace & $\mathrm{F}$ & 4 & e9 & 0.05 \\
\hline Epidemiology & $\mathrm{F}$ & 15 & e10 & 0.18 \\
\hline Demographics & $\mathrm{F}$ & 3.5 & e11 & 0.04 \\
\hline Sociology & $\mathrm{F}$ & 10 & e12 & 0.12 \\
\hline Oncology & M & 7 & e13 & 0.08 \\
\hline
\end{tabular}

F: female; M: male.

relevant with 9.52, preceded by following the doctor's advice, trusting the doctor and followup of abnormal Pap results.

8) Proximity and density of facilities, physicians: of the nine variables, four were retained, the availability of mammographs having the highest score with 9.44 , followed by health communication through workshops, density of radiologists and availability of health centers.

9) Crowding, scheduling and convenience latent variable: the longer than average waiting time for a consultation was the factor retained with 7.10.

\section{Discussion}

The theory proposes that a variety of contextual factors operating at different levels of influence can help explain female participation in breast cancer screening. This study has examined the theoretical model of the ecological environment for mammography use proposed by Mobley et al. 16 in the Mexican context.

The selection procedure and importance of the factors which affect the screening uptake was determined by expert survey, i.e. having experts from the practice validate it, and Fuzzy Delphi Method analysis. The use of the Fuzzy Delphi Method helps to solve the uncertainty of an accurate expert distinction in the examination of the features during the survey process, ensuring a better quality of survey analysis.
One of the great advantages of the Fuzzy Delphi Method is the time saved in obtaining results, compared to the classic Delphi. The degrees of importance of participants affected the group decision-making, i.e. some experts are more experienced with breast cancer screening studies than others. Thus, by applying the Consistency Aggregation Method the fuzzy individual opinions are combined to obtain group consensus opinions, considering the relative weight of each expert according to their years of experience in mammography studies.

Several authors mentioned that the use of mammography can be determined by the term and type of medical insurance 6,28,29. De Alba et al. 30 and Garbers et al. 31 reported that lower participation rates are primarily associated with low socio-economic levels and health care barriers. Women believe that child-care issues influence the lack of follow-up mammograms $32,33,34,35$. Our results of asset index and having children, as factors influencing mammography participation are consistent with previous studies 6,28,29,30,32,33,34,35. As Brouwers et al. 36 reported, there is no evidence that group education has an effect on mammography adherence. However other studies reported a link between having a higher level of education and being receptive to mammography 7,28,29,35.

Participation in mammography screening by the women in this study appears determined by "need factors". Age of first childbirth is one of the 
Figure 3

Expert opinion represented as a Fuzzy set (x-axis) and the corresponding membership function ( $y$-axis)

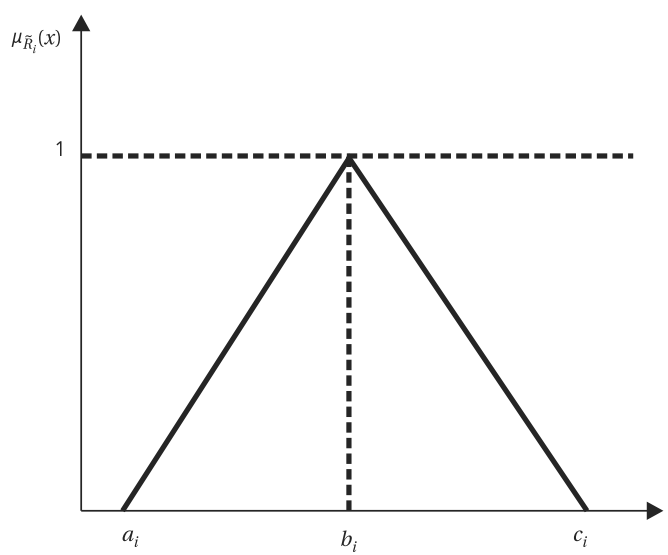

risk factors for breast cancer 37 . Sclowitz et al. 38 concluded that, at least with regard to the clinical breast exam, having a higher risk is positively related to the test. A number of preventive care variables such as influenza vaccination, bone density screening, Pap or gynecologic exam 39 and other disease prevention behaviors 37 were strongly associated with mammography. Moreover, in a study of Mexican women aged between 20 and 49, undergoing at least one Pap test was found to be linked with the carrying out of mammograms 6 . Our research is the first study to use fuzzy logic that has identified the Pap smear as a factor that may affect screening rates. This finding is consistent with mathematical modeling studies among Mexican women ${ }^{6}$ and elsewhere 40,41 . There is general agreement with the broad conclusions of the Canadian Cancer Society study, which reported that improved health care systems, strategies and policies must include the integration of primary cancer prevention with other chronic disease prevention activities 42 .

Our study confirms that among the barriers to the best breast cancer healthcare in developing countries, more so at low income levels, are lack of knowledge of the disease, socio-economic and cultural barriers, organizational problems, poor quality health services and limited resources $35,37,40,41$. Case studies supporting our findings, have suggested that the synergy between elements such as: anti-poverty strategies, collaboration of NGOs with the government, empowerment through employment 42 , participa- tive development and active health programs may be the most effective in improving health and development outcomes 37 . However, besides raising women's income-generating capacity, it is also necessary to increase their autonomy, decision-making authority, mobility and power in the home.

Other mamography participation studies have also found a lack of health-related social support as a barrier for the use of early detection tests $40,41,42$. Health-related social support may be forthcoming from a regular doctor, but also refers to engaging in conversations with other women about health-related issues, for example providing information and clearing up any doubts about the exam.

Our findings related to the association between screening uptake and health behaviors, proximity-density of facilities and stressors, are consistent with the results documented by Brouwers et al. 36 and the Canadian Cancer Society 43 . In a cohort of women with initial ages of 35 to 39 years, those who had false-positive mammography outcomes showed less risk of non-participation in the future, compared to those who had true-negative outcomes ${ }^{37}$. Similarly, women with abnormal Pap smears were significantly more adherent to mammography than those with normal results 37 . Particularly in the clinical breast exam 40 and breast cancer screening 41,42 , one barrier which dampens demand is users' confidence in health care personnel and in the organizational aspects of the institutions which provide the service. Furthermore, the recommendation of doctors is vital because the physician's advice to have a mammogram persuades individuals to adopt that preventive health behavior 37,40,41,42. Unger-Saldaña \& Infante-Castañeda 44 maintain that the national screening program implies the equitable cost and distribution of mammography equipment, in addition to the training and adequate distribution of personnel to perform and interpret the test. The perception that the health system has sufficient equipment, staff and time to carry out the test also bore a significant relation to the breast cancer screening 35,37 .

Our findings support the argument that the lack of effective communication in health care 42 and lack of knowledge about cancer 35,45 are determining factors for poor mammography participation 40 . Thus, a reduction of structural barriers, giving provider assessment and feedback is recommended to improve screening rates 39 as well as ensuring an adequate supply of cancer prevention scientists and practitioners ${ }^{42}$. Disparities in access to and quality of health services, for example, and an acceptable waiting time for obtaining a breast cancer exam 35 have 
been identified in and within various regions of Mexico, affecting poorer women to a greater degree 41 . Our result of consultation wait times as a possible determinant of mammography utilization is consistent with this finding.

Examination of the threshold values showed that experts generally ranked highly those variables that related to predisposing and proximitydensity of facilities and physicians. Early diagnosis, therefore, requires a process of effective communication and education which inculcates the medical culture of prevention in the population 46 Consequently, the best alternative is to renew early cancer detection strategies and programs rather than continuing the identification of patients in later stages when there will be insufficient resources for adequate treatment 4 . The findings described above coincide with some of today's challenges for the efficient detection of breast cancer such as: (1) promoting equal investment in human resources, infrastructure and screening equipment, (2) improving information and target population awareness-raising about the benefits associated with early detection, (3) training enough radiology technicians, oncology specialist nurses among others and (4) promoting a culture of quality and excellence in the provision of services ${ }^{5}$.

\section{Conclusion}

The present study suggests that population health behaviors, i.e. follow-up of abnormal mammogram results and/or abnormal Pap results, following the doctor's advice and trusting the doctor, is the most relevant latent variable that could determine women's mammography participation. This shows, therefore, that some women may be less willing and less concerned about their health, demonstrating a bigger risk of non-participation in preventive health behavior in the future. According to the next highest scores obtained from the Consistency Aggregation Method, proximity-density of facilities and physicians, as well as stressors, are also relevant latent variables associated with adherence to early breast cancer detection. Additional research to balance and increase the number of experts in the various areas of specialization to obtain more reliable conclusions, to use other transformation methods for defuzzification in the proposed algorithm and to study the risk of breast cancer through Fuzzy Rule-Based System, is also needed. Moreover, additional studies addressing factors like quality and optimization of health services, training of personnel at all levels, formality and seriousness when dealing with patients, self-esteem, body image, taboos and psycho-social factors are suggested.

\section{Resumo}

No México, a participação regular em mamografia refere baixa frequência, mesmo que acrescentada a sobrevivência. O objetivo desta investigação é destacar os procedimentos que precisam ser otimizados e áreas de investimento, para aumentar a conscientização sobre os benefícios do diagnóstico precoce. Tais características socioecológicas (comunidades, interpessoais e individuais) foram registradas por meio da revisão da literatura e do modelo de interação espacial do uso da mamografia desenvolvido pelo Mobley et al. As opiniões de especialistas sobre a importância dessas características foram recolhidas por uma pesquisa, utilizando o método Fuzzy Delphi para reduzir a incerteza implícita.
Nossos resultados sugerem que os comportamentos de saúde da população, proximidade e densidade de instalações e médicos, bem como fatores predisponentes, são essenciais para acrescentar as taxas de testes. O uso de painéis desiguais em tamanho poderia afetar a confiabilidade das conclusões. A aplicação do método de agregação modificada forneceu um consenso do grupo menos sensível a um mal-entendido, além de avaliar a importância de cada especialista de acordo com a sua experiência de investigação com a mamografia.

Mamografia; Zonas Rurais; Métodos 


\section{Contributors}

A. P. Sánchez-Lezama contributed to the study design, data collection, analysis, interpretation of the results and writing. J. Cavazos-Arroyo and C. Albavera-Hernández collaborated with the study design, writing and final approval of the article.

\section{Acknowledgments}

Funding support for the data collection of 2007 rural Households Evaluation Survey (ENCEL-2007) was provided by the Mexican Ministry of Social Development, represented by Oportunidades.

\section{References}

1. Lozano-Ascencio R, Gómez-Dantés H, Lewis $\mathrm{S}$ Torres-Sánchez L, López-Carrillo L. Tendencias del cáncer de mama en América Latina y el Caribe. Salud Pública Méx 2009; 52 Suppl 2:S147-56.

2. American Cancer Society. Breast cancer facts \& figures: 2007-2008. Atlanta: American Cancer Society; 2007.

3. Ries LAG, Harkins D, Krapcho M, Mariotto A, Miller BA, Feuer EJ, et al. SEER cancer statistics review. Bethesda: National Cancer Institute; 2005.

4. Mohar A, Bargalló E, Ramírez MT, Lara F, BeltránOrtega A. Recursos disponibles para el tratamiento del cáncer de mama en México. Salud Pública Méx 2009; 52 Suppl 2:S263-9.

5. Martínez-Montañez OG, Uribe-Zúñiga P, Hernández-Ávila M. Políticas públicas para la detección del cáncer de mama en México. Salud Pública Méx 2009; 52 Suppl 2:S350-60.

6. Sosa-Rubí S, Walker D, Serván E. Práctica de mastografías y pruebas de Papanicolaou entre mujeres de áreas rurales de México. Salud Pública Méx 2009; 52 Suppl 2:S236-45.

7. Somers TJ. Risk behaviors in a community sample of women with a family history of breast cancer [Doctoral Dissertation]. Pittsburgh: University of Pittsburgh; 2006.

8. Glumac B, Han Q, Smeets JJAM, Schaefer WF. Brownfield redevelopment features: applying Fuzzy Delphi. Journal of European Real Estate Research 2011; 4:145-59.
9. Hsu Y, Lee C, Kreng VB. The application of Fuzzy Delphi Method and Fuzzy AHP in lubricant regenerative technology selection. Expert Syst Appl 2010; 37:419-25.

10. Murray TJ, Pipino LL, Gigch JP. A pilot study of fuzzy set modification of Delphi. Human Systems Management 1985; 5:76-80.

11. Kahraman C, Cebeci U, Ruan D. Multi-attribute comparison of catering service companies using fuzzy AHP: the case of Turkey. International Journal of Production Economics 2004; 87:171-84.

12. Zadeh LA. Fuzzy sets. Information Control 1965; 8:338-53.

13. Ju H, Wang F. A similarity measure for intervalvalued Fuzzy Sets and its application in supporting medical diagnostic reasoning. In: Proceedings of the 10th International Symposium on Operations Research and Its Applications (ISORA 2011. Dunhunag: World Publishing Corporation; 2011. p. 251-7.

14. Qiu J, Sun T, Shi, Y. The absolute continuity of fuzzy complex measures. ICIC Express Letters 2007; 1:27-32.

15. Lu C, Lan J, Wang Z. Aggregation of fuzzy opinions under group decision-making based on similarity and distance. Journal of Systems Science and Complexity 2006; 19:63-71. 
16. Mobley LR, Kuo M, Driscoll D, Clayton L, Anselin C. Heterogeneity in mammography use across the nation: separating evidence of disparities from the disproportionate effects of geography. Int J Health Geogr 2008; 7:1-18.

17. MacCallum RC, Austin JT. Applications of structural equation modeling in psychological psychological research. Annu Rev Psychol 2000; 51:201-26.

18. Schulz A, Kannan S, Dvonch J, Israel B, Allen A, James S, et al. Social and physical environments and disparities in risk for cardiovascular disease: the healthy environments partnership conceptual model. Environ Health Perspect 2005; 113:1817-25.

19. Secretaría de Desarrollo Social. Evaluación externa, bases de datos y cuestionarios. Encuesta de Evaluación de los Hogares 2007: ENCEL 2007. http://evaluacion.oportunidades.gob.mx:8010/ es/bases_cuan_c.php (accessed on 15/May/2011).

20. Park JW, Yun YS, Kang KH. The mean value and variance of one-sided fuzzy sets. Journal of the Chungcheong Mathematical Society 2010; 23: 511-21.

21. Bartels F. Fuzzy kriging: basics. Theoretical concepts. http://www.fuzzeks.de/helptext/Kri_basi. $\mathrm{htm}$ (accessed on 01/Sep/2011).

22. Merigó JM. Using the probabilistic weighted average in decision making with distance measures. In: Proceedings of the World Congress on Engineering. London: Imperial College London; 2010. p. 1-4.

23. Kaufman A, Gupta MM. Introduction to fuzzy arithmetic: theory and applications. $2^{\text {nd }}$ Ed. New York: van Nostrand Reinhold; 1985.

24. Bai Y, Zhuang H, Wang D. Advanced fuzzy logic technologies in industrial applications. London: Springer; 2006.

25. Agudelo M, Aguirre A, Dávila C. Variaciones en los años de vida perdidos por cánceres de mama y cérvico uterino en México según grado de marginación estatal, 1997 y 2007. Rev Chil Salud Pública 2010; 14:8-17.

26. Ho YF, Wang HL, Lu CH. The dynamic simulation model for the sustainable development of taichung city. Journal of Architecture 2002; 41:107-28.

27. Ho YF, Wang HL. Applying fuzzy Delphi method to select the variables of a sustainable urban system dynamics model. In: Proceedings of the $26^{\text {th }}$ International Conference of System. http://www. systemdynamics.org/conferences/2008/proceed/ (accessed on 15/May/2011).

28. Couture MC, Nguyen CT, Alvarado BE, Velasquez LD, Zunzunegui MV. Inequalities in breast and cervical cancer screening among urban Mexican women. Prev Med 2008; 47:471-6.

29. Naivar CK. Factors associated with mammography utilization in Sao Paulo and Mexico city elderly females [Doctoral Dissertation]. Houston: University of Texas School of Public Health; 2008.

30. De Alba I, Hubbell AF, McMullin JM, Sweningson JS, Saitz R. Impact of U.S. citizenship status on cancer screening among immigrant women. J Gen Intern Med 2005; 20:290-6.

31. Garbers S, Jessop DJ, Foti H, Uribelarrea M, Chiasson MA. Barriers to breast cancer screening for low-income Mexican and Dominican women in New York City. J Urban Health 2003; 80:81-91.
32. Livaudais J, Coronado GD, Espinoza N, Islas I, Ibarra G, Thompson B. Educating Hispanic women about breast cancer prevention: evaluation of a home-based promotora-led intervention. J Womens Health 2010; 19:2049-56.

33. Salazar MK. Hispanic women's beliefs about breast cancer and mammography. Cancer Nurs 1996; 19:437-46

34. Thomas E. From qualitative data to instrument development: the women's breast conflict scale. Qual Rep 2011; 16:908-32.

35. Wall KM, Núñez-Rocha GM, Salinas-Martínez AM, Sánchez-Peña SR. Determinants of the use of breast cancer screening among women workers in urban Mexico. Prev Chronic Dis 2008; 5:1-8.

36. Brouwers MC, De Vito C, Bahirathan L, Carol A, Carroll JC, Cotterchio M, et al. Effective interventions to facilitate the uptake of breast, cervical and colorectal cancer screening: an implementation guideline. Implement Sci 2011; 6:112.

37. Fitzpatrick JJ, Wallace M. Encyclopedia of nursing research. 2nd Ed. New York: Springer; 2006.

38. Sclowitz ML, Baptista AM, Petrucci D, Tessaro S. Condutas na prevenção secundária do câncer de mama e fatores asociados. Rev Saúde Pública 2005; 39:340-9.

39. Wilkinson JE, Lauer E, Freund KM, Rosen AK. Determinants of mammography in women with intellectual disabilities. J Am Board Fam Med 2011; 24:693-703.

40. González P, Borrayo EA. Role of physician involvement on Latinas' mammography screening adherence. Womens Health Issues 2011; 21:165-70.

41. Otero-Sabogal R, Owens D, Canchola J, Golding JM, Tabnak F, Fox P. Mammography rescreening among women of diverse ethnicities: patient, provider, and health care system factors. J Health Care Poor Underserved 2004; 15:390-412.

42. Nigenda G, Caballero M, González-Robledo LM. Access barriers in early diagnosis of breast cancer in the Federal District and Oaxaca. Salud Pública Méx 2009; 52 Suppl 2:S254-62

43. Canadian Cancer Society; Cancer Care Ontario. Targeting cancer: an action plan for cancer prevention and detection (Cancer 2020). Toronto: Cancer Care Ontario; 2003.

44. Unger-Saldaña K, Infante-Castañeda C. Delay of medical care for symptomatic breast cancer: a literature review. Salud Pública Méx 2009; 52 Suppl 2:S270-85.

45. Bird Y, Banegas MP, Moraros J, King S, Prapasiri S, Thompson B. The Impact of family history of breast cancer on knowledge, attitudes, and early detection practices of Mexican women along the Mexico-US border. J Immigr Minor Health 2011; 13:867-75.

46. Morales A, Morimoto S, Natsuko O, Díaz V. Cáncer de glándula mamaria parte II. Revista de la Escuela de Medicina “Dr. José Sierra Flores” 2009; 23:16-22.

Submitted on 06/Feb/2013

Final version resubmitted on $04 / \mathrm{Sep} / 2013$

Approved on 17/Sep/2013 